\title{
INFLUENCE OF TOPICAL BROWN ALGAE (CYSTOSEIRA MYRICA) EXTRACT APPLICATION ON WOUND HEALING IN RATS.
}

\author{
Ayman Atiba ${ }^{1}$, Walied Abdo ${ }^{2}$, Fedekar F. Madkour, ${ }^{3}$ \\ 1 Departments of Surgery, Anaesthesiology and Radiology, Faculty of \\ Veterinary Medicine, Kafrelsheikh University, Egypt. \\ 2 Department of Veterinary Pathology, Faculty of Veterinary Medicine, \\ Kafrelsheikh University, Egypt. \\ ${ }^{3}$ Marine Science Department, Faculty of Science, Port Said University, Egypt.
}

\section{ABSTRACT}

Objectives: To investigate the feasibility and safety of brown algae (Cystoseira myrica) extract in the improvement of wound healing process.

Materials and Method: Full thickness excision wounds $(1.5 \times 1.5 \mathrm{~cm})$ were created under general anesthesia on the back of the rats. These rats were divided into two groups; control group (Group C) and brown algae extract topical application group (Group B). Each wound area was measured on days 0, 3, 6, 9, 12, 15 and 18 postwounding. On day 18 post-wounding, animals were sacrificed. Quantification of granulation tissue and their biochemical and histological aspects in control as well as treated groups were estimated.

Results: Brown algae extract showed significant increase in wound contraction and formation of scars on days 9, 12, 15 and18 post wounding ( $p<0.001)$. Histologically, extracellular matrix deposition and epithelialization were promoted in Group B. 
Conclusion: The present results suggest that brown algae (Cystoseira myrica) extract can effectively improve wound healing in a fullthickness skin wound model. Use of brown algae (Cystoseira myrica) extract might therefore facilitate development and improvement of wound healing treatments in future.

Keywords: Brown algae, Cystoseira myrica, Skin, Wound healing.

\section{INTRODUCTION}

Cutaneous wound healing is a complex process involving a series of sequential and overlapping phases, including inflammation, proliferation, and remodeling. This process requires interactions between a variety of cell types, multiple cytokines, growth factors, and extracellular matrix (ECM) molecules [1]. Therapeutic goals in wound management include prevention of infections and rapid healing with the least side effects. Given the adverse effects of currently used topical antibiotics, introduction of novel topical agents that could effectively and safely promote wound healing and relieve the associated pain are desirable. Based on traditional medicine, studies have shown improvement in the healing process with the use of natural resources notably plants, animals, and fungi [2]. Often their use is merely based on tradition, without any scientific evidence of efficacy and little knowledge about putative active compounds or their mode of actions.

During recent years, the interest in marine organisms as a potential and promising source of pharmaceutical agents has increased (3). Marine algae or seaweeds are considered as a source of bioactive compounds as they are able to produce a great variety of secondary metabolites which acts as potential bioactive compounds of interest for pharmaceutical Kafrelsheikh Vet. Med. J. Vol. 11 No. 1 (2013) 
applications (4). Brown algae are a group of seaweeds that are recognized as rich source of alginates (5), which have therapeutic potential for wound treatment $(6,7)$. The algae Cystoseira myrica (S.G. Gmelin) C. Agardh, belongs to family: Sargassaceae, is a brown seaweed widely distributed in the Egyptian Red Sea shores. The effect of brown algae (Cystoseira myrica) extract on wound healing is not yet well elucidated. Hence, the present study was undertaken to study the influence of extract from brown algae (Cystoseira myrica) on healing of full-thickness skin wound excision in rats.

\section{MATERIAL AND METHODS}

\section{Preparation of algal extract:}

The brown algae, Cystosira myrica, were collected from the Egyptian coast of Red Sea at Hurghada during autumn 2012, Figure (1). After collection, the seaweeds were cleaned by washing several times with tap water then with distilled water to remove any epiphytes, salts, sands or any debris. It was then air-dried in shade at room temperature and coarsely powdered. The dried powdered plants tissue was extracted three times with aqueous ethanol (70\%) at room temperature with occasional shaking. The extract was filtered then evaporated by rotator evaporator at $40^{\circ} \mathrm{C}$ under negative pressure. The resulting concentrated crude extract was used for the animal experimentation.

\section{Animals:}

Seven to eight-week-old male Wistar rats weighing 160-200 g were used in this experiment. Animals were housed one per cage for one week prior to the experiment for accommodation. Animals were fed 
commercial rat food and water ad libitum. These rats were treated in accordance with the guideline for animal care.

\section{Animal grouping:}

Animals were randomly assigned into two groups (6 animals each); control group (Group C), which was without treatment and brown algae extract topical application group (Group B).

\section{Experimental wounding:}

All rats were anesthetized with mix of ketamine and xylazine (60 $\mathrm{mg} / \mathrm{kg}$ ketamine and $6 \mathrm{mg} / \mathrm{kg}$ xylazine) by intraperitoneal (IP) injection. The hair on the back of each animal was shaved and sterilized with $70 \%$ alcohol. Full-thickness skin wound excision measuring $1.5 \times 1.5 \mathrm{~cm}$ was made on the back of each animal. The wound was photographed on the day of surgery (day 0) and subsequent days (days 3, 6, 9, 12, 15 and 18 post-wounding). The photos were transferred to the computer, changed to Tagged Information File Format extension using Adobe ${ }^{\circledR}$ Photoshop ${ }^{\circledR}$ Elements ${ }^{\circledR} 4.0$ software (Adobe Systems, Tokyo, Japan). Wound area was measured by NIH Image $\mathbf{J}$ software (downloaded from http://www.rsb.info.nih.gov/ij). The contraction in wound size was expressed as a percentage to the original wound size (day 0: 100\%).

\section{Tissue Collection:}

Rats were euthanized by over dose of anesthesia on day 18 postwounding. The entire wound with a margin of approximately $5 \mathrm{~mm}$ of surrounding unwounded skin was excised. These wound samples were used for histopathological examination and was fixed for $48 \mathrm{hr}$ in a $10 \%$ buffered formalin solution ( $\mathrm{pH}$ 7.4) and embedded in paraffin. 


\section{Histological analysis:}

Sections $(5 \mu \mathrm{m})$ were cut and stained with hematoxylin and eosin (H\&E) for histopathological examination. Wound granulation tissue was graded in a blind manner using a modified 0 to 4 Ehrlich and Hunt Numerical scale, in which 0 ; no evidence, 1 ; occasional evidence, 2; light scattering, 3; abundant evidence, 4; confluent cell or fibers (8). The evaluated features were inflammatory cells infiltration (white blood cell count), ECM deposition, angiogenesis and degree of epithelialization (expressed as a percentage of epithelialization in relation to wound size). Two separated sections of each wound were examined by light microscopy. Each score of the features was assessed individually in 8 high-power fields (x 400) over 2 separated sections. The calculated values are shown as means \pm standard deviation (SD).

\section{Statistical analysis:}

Results were expressed as mean \pm SD. Differences between more than two means were determined by ANOVA followed by Students't test. Values of $\mathrm{P}<0.05$ were considered statistically significant. Statistical analysis was performed using the software GraphPad Prism version 5.0 (GraphPad Software Inc., San Diego, CA, USA).

\section{RESULTS}

\section{Wound contraction:}

The difference in wound contraction (expressed as a percentage of the wound area to the wound area on day (0) between Group $\mathrm{C}$ and Group B was shown in Figure (2). Wound contraction in Group B was accelerated significantly in compare to Group $\mathrm{C}$ on days $3,6,9,12,15$ and 18 post-wounding $(\mathrm{P}<0.05)$. 


\section{Histological analysis:}

Histological scoring on day 18 post wounding, Group B showed an increase in epithelialization rate and ECM deposit mainly collagen compared with Group C. Moreover, the decrease in cellular infiltration and angiogenesis also had been noticed (Fig. 3).

The results of histological grading scale on day 18 post-wounding were shown in Table 1. Histological evaluation of the wound region revealed that inflammatory cell infiltration score was significantly lower in Group B $(\mathrm{P}<0.05)$. Angiogenesis score was significantly lower in group B $(\mathrm{P}<0.05)$. ECM deposit was significantly higher in Group B ( $<0.01)$. The percentage of epithelialization was significantly higher in Group B $(\mathrm{P}<0.05)$.

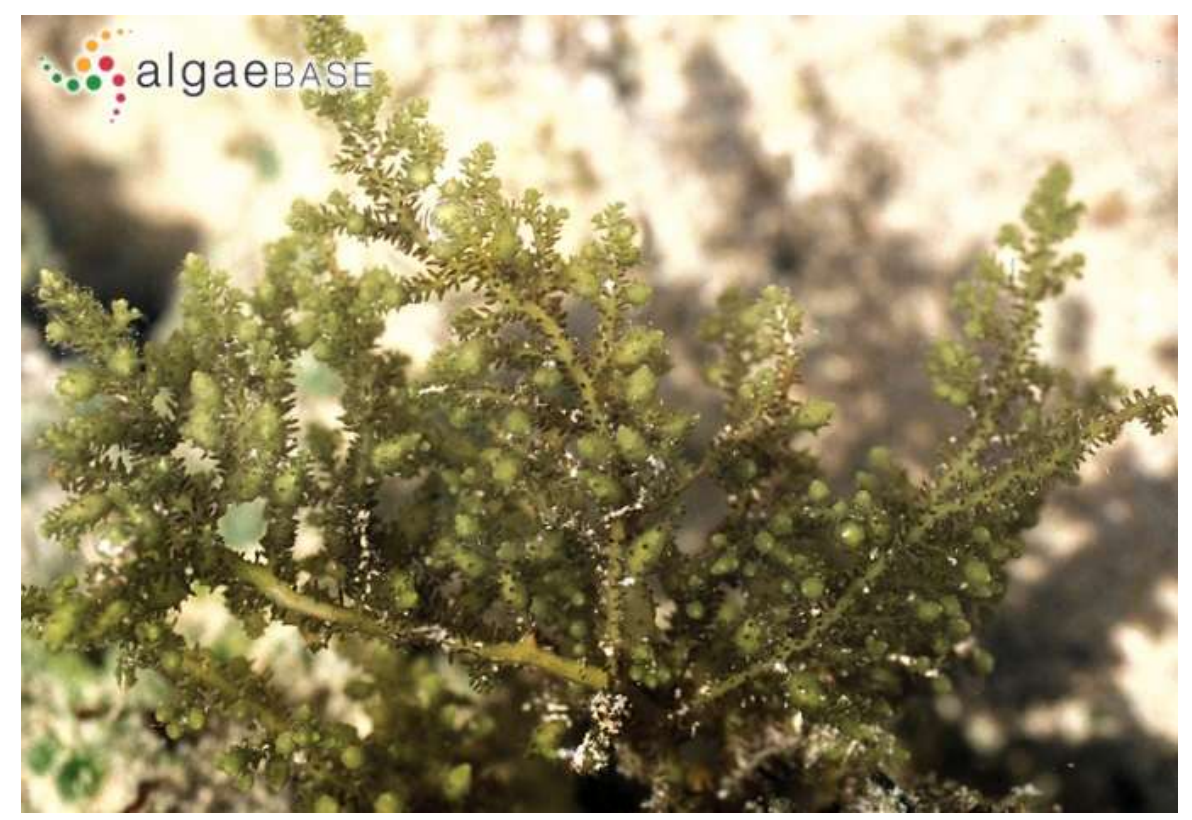

Fig. (1): Cystoseira myrica (S.G.Gmelin) C.Agardh (download from http://www.algaebase.org/search/species/detail/?species_id=11399) 


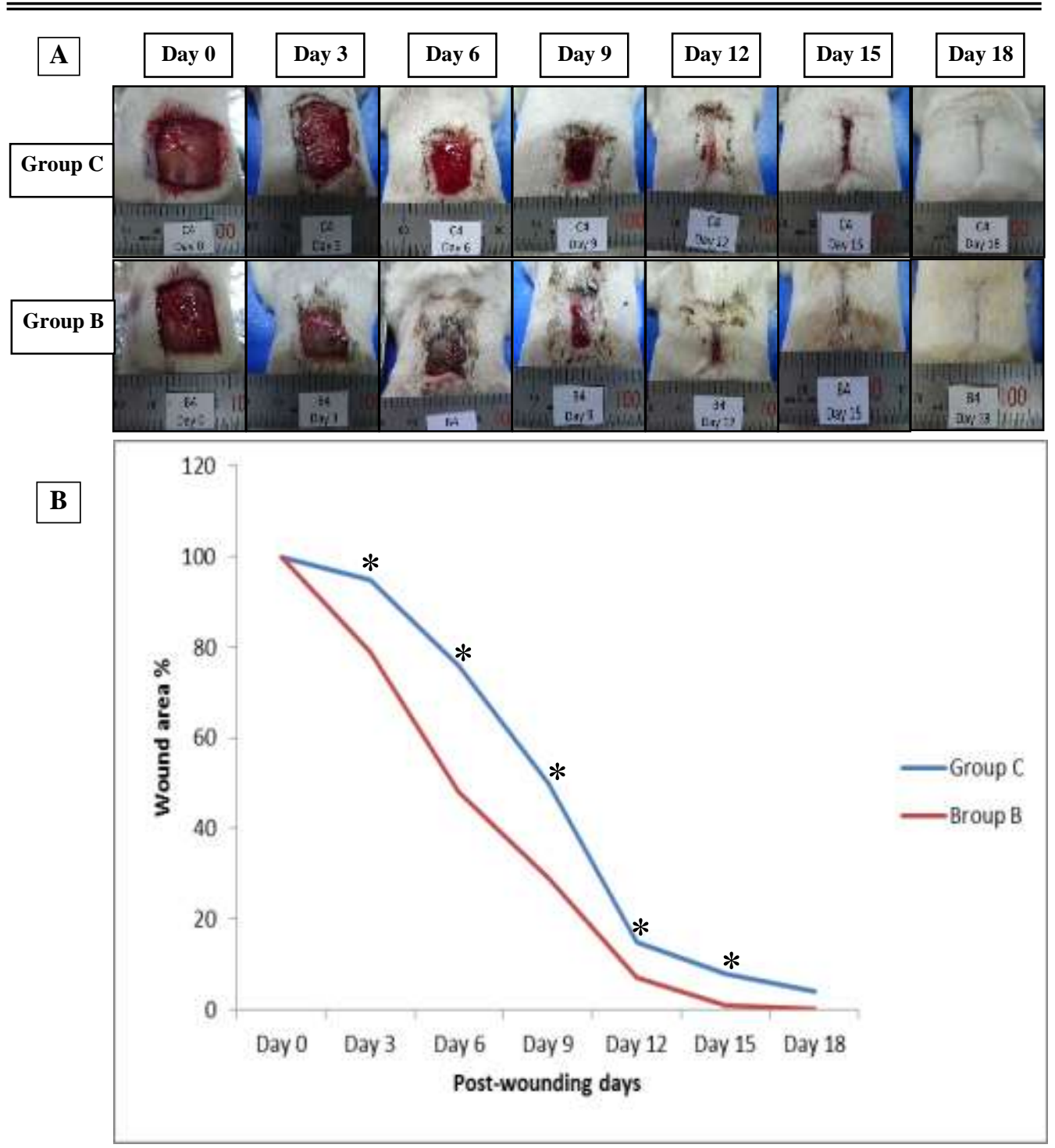

Fig. (2): Photo from the macroscopic evaluation of the wounds in the control and the brown algae groups on days $0,3,6,9,12,15$, and 18 postwounding days (A). Evaluation of the wound contraction in the control (Group C) and the brown algae (Group B) (B). Data are expressed as the percentage of the initial wounded area, as the mean $\pm \mathrm{SD}(* P<0,05)$. 
Ayman Atiba et., al.

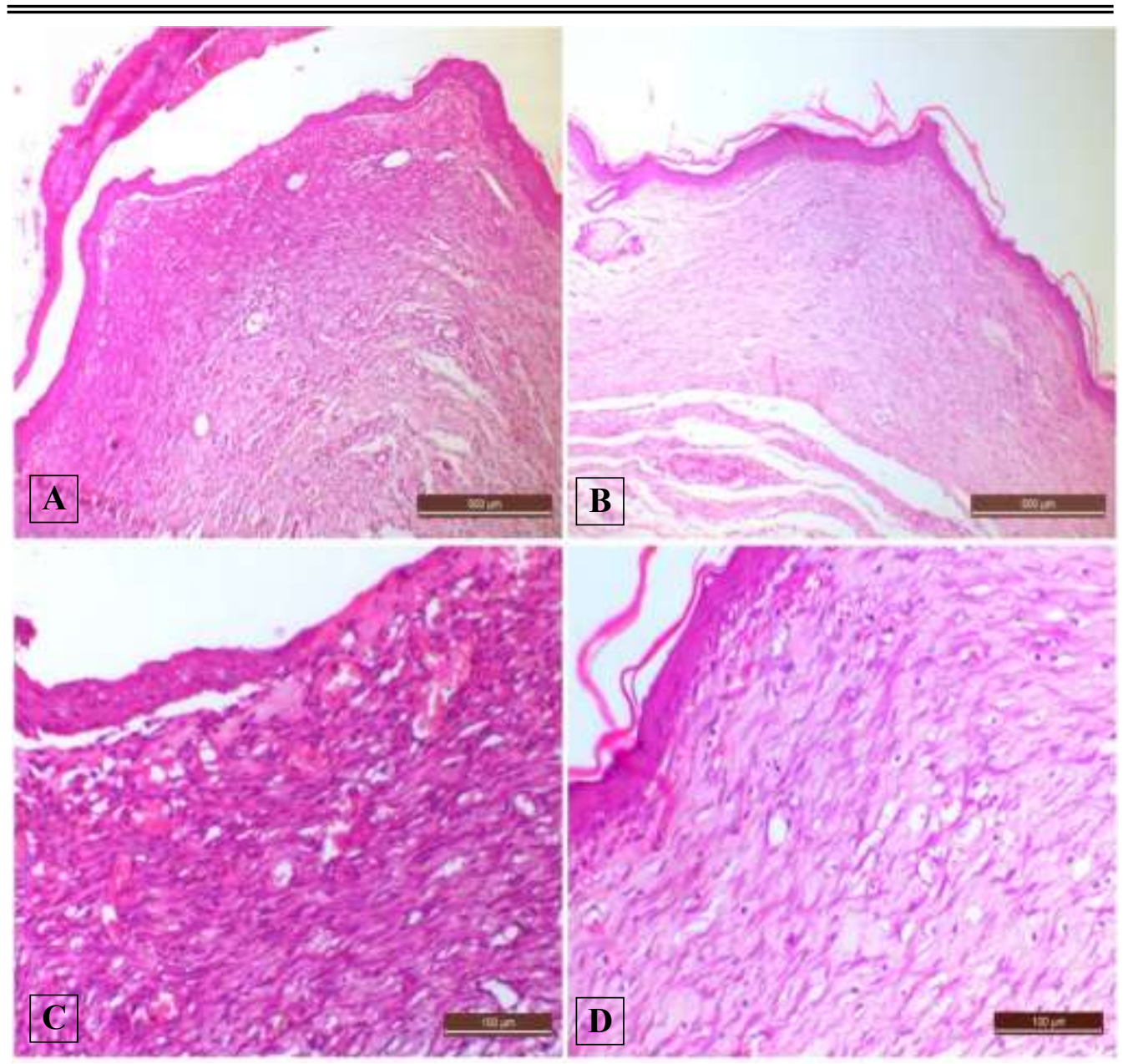

Table (1): Histological grading scores on day 18 post-wounding.

\begin{tabular}{|c||c||c||c||c||}
\hline Parameter & $\begin{array}{c}\text { inflammatory } \\
\text { cells infiltration }\end{array}$ & Angiogenesis & $\begin{array}{c}\text { ECM } \\
\text { deposition }\end{array}$ & $\begin{array}{c}\text { degree of } \\
\text { epithelialization }\end{array}$ \\
\hline \hline Group C & $3.3 \pm 0.21^{*}$ & $2.9 \pm 0.53$ & $1.7 \pm 0.91$ & $63 \pm 16$ \\
\hline Group B & $0.4 \pm 0.61$ & $1.4 \pm 0.69$ & $3.2 \pm 0.46^{*}$ & $87 \pm 13^{*}$ \\
\hline
\end{tabular}

Histological scale means 0 ; no evidence, 1; occasional evidence, 2;

light scattering, 3; abundant evidence, 4; confluent cell or fibers. Epithelialization (\%) expressed as a percentage of epithelialization in relation to wound size. ${ }^{*} \mathrm{P}<0.05$ significant 


\section{DISCUSSION}

The wound healing process has been long studied, and has been typically divided into three phases: inflammation and hemostasis, proliferation and migration, and remodeling/maturation (9).

Interest in employing wound healing promoting compounds from natural sources like plants or algae has been enhanced by researchers and the consumers' preference for natural medicines and concerns about the toxic effects of synthetic materials. Therefore, the discovery of natural wound healing promoting compounds should be interesting. To date, several plants have been used to accelerate wound healing, such as Aloe vera (10). Marine plants have yielded a variety of secondary metabolites that possess novel chemical structures and interesting pharmacological activities (11). Recently, researchers have described a wide range of biological activities for algal compounds including anti-HIV, anticoagulant, anticonvulsant, anti-inflammatory, antineoplastic, and cytotoxic activities $(12,13)$. However, until now there has been no other study on the wound healing effect of C. myrica. This was valuable for us especially because we had easy access to this alga in the Egyptian Red Sea shores. In the present study, wound healing properties of brown algae (Cystoseira myrica) were studied and the findings of the present study indicate that topical application of brown algae extract promotes the wound healing process.

Wound contraction involves a complex and superbly orchestrated interaction of cells, extracellular matrix, and cytokines (9). The increased 
rate of wound contraction in brown algae-treated wounds might be attributed to increased proliferation and transformation of fibroblast cells into myofibroblasts. Histological findings also showed enhanced proliferation of fibroblasts and reepithelialization in brown algae-treated wound tissues.

The fibroblasts are responsible for the synthesis, deposition, and remodeling of ECM (9). After migrating into wounds, fibroblasts initiate the synthesis of ECM. Collagen is a major protein of ECM and is the component that ultimately contributes to wound strength (1). The enhanced levels of ECM (collagen) in brown algae-treated rats probably provide the strength to the regenerated tissue.

Alginates are quite abundant in brown algae, they occur as a structural component, compromising up to $40 \%$ of the dry matter (5). Alginate dressings maintain a physiologically moist microenvironment that promotes healing and the formation of granulation tissue (14). Alginates may influence wound healing in a number of ways not yet fully understood (15).

\section{Conclusion:}

The results of the current study indicated that brown algae (Cystoseira myrica) are a potential wound-healing agent in rat models of wound. Further studies are needed to elucidate the mechanism of action and the nature of the chemically active constituents responsible for the wound healing activities of brown algae (Cystoseira myrica). 


\section{REFERENCES}

- Li J., Chen J., and Kirsner R., (2007): Pathophysiology of acute wound healing, Clinics in Dermatology, vol. 25, no. 1, pp. 9-18.

- Reuter J., Merfort I.,Schempp CM.(2010): Botanicals in dermatology: an evidence-based review. Am J Clin Dermatol; 11 (4): 247-67

- Kim I.H. and Lee J.H. (2008): Antimicrobial activities against methicillinresistant Staphylococcus aureus from macroalgae. J. Ind. Eng. Chem., 14: 568-572.

- Solomon R.D.J. and Santhi V.S. (2008): Purification of bioactive natural product against human microbial pathogens from marine seaweed Dictyota acutiloba, J. Ag. World J. Microbiol. Biotechnol., 24: $1747-1752$.

- Draget K. I, Smidsrod O. and Skjak-Brak G. (2005): Alginates from Algae. Biopolymers Online, Wiley-VCH Verlag GmbH \& Co. KGaA

- Sedlarik K.M. (1993): Alginates for wound curing. Khirurgiya $1,62-65$.

- Barnett S. E. and Varley S. J. (1987): The effects of calcium alginate on wound healing. Ann R Coll Surg Engl. July; 69(4): 153-155.

- Philips J.D, Kim C.S, Fonkalsrud E.W, Zeng H.and Dindar H. (1992): Effects of chronic corticosteroid and vitamin A on the healing of intestinal anastomoses. Am J Surg; 163: 71-77. 
- Gurtner G.C, Werner S., Barrandon Y. and Longaker M.T. (2008): Wound repair and regeneration. Nature.;453:314-21.

- Atiba A, Ueno H, Uzuka Y. (2011): The effect of aloe vera oral administration on cutaneous wound healing in type 2 diabetic rats. $J$ Vet Med Sci. May;73(5):583-9.

- Stonik V. A., and Elyakov G. B. (1986): Bio-Organic Marine Chemistry, Vol. 2, 43-86, Springer-Publ., Berlin

- Lincoln R. A., Strupinski K., and Walker J. M. (1991): bioactive compounds from algae. Life Chem. Rep. 8,97-183.

- Ayyad SE, Abdel-Halim OB, Shier WT and Hoye TR. (2003): Cytotoxic hydroazulene diterpenes from the brown alga Cystoseira myrica. Z Naturforsch C. Jan-Feb;58(1-2):33-8.

- Motta G.J., (1989): Calcium alginate topical wound dressings: a new dimension in the cost-effective treatment for exudating dermal wounds and pressure sores; Ostomy Wound Manage; 25:52-56.

- Thomas S. (2000): Alginate dressing in surgery and wound management - part1. J wound Care. Feb, 9 (2); 56-60. 